\title{
Design Method of B-Axis Components of Water Chamber Head Turning and Milling Machining Center
}

\author{
Zheng Minli ${ }^{*}, 1$, Cheng Fenglan ${ }^{1}$, Zhao Jiaxue ${ }^{1}$, Sun Shouzheng ${ }^{1}$ and Jiang Chongmin ${ }^{2}$ \\ ${ }^{l}$ National \& Local United Engineering Laboratory of High Efficiency Cutting and Tools, Harbin University of Science \\ and Technology, Heilongjiang, Harbin, 150080, P.R. China; ${ }^{2}$ Qiqihar No.2 Machine Tool (Group) Co., Heilongjiang, \\ Qiqihar, 161000, P.R. China
}

\begin{abstract}
Aiming at the demands of nuclear water chamber head's multi-inclined holes and ramps in boring and milling, based on design requirements of special turning and milling machining center, B-axis structural design is put forward, research on deformation characteristics of ram components under different swing angle, propose the control methods of deformation and errors. Adopt modeling method of equal mass, construction of deformation and displacement analysis model of B-axis components, explore formation reason of maximum gap between components' joint surface, form optimization design scheme of rotation structure of B-axis components. Trial-produce prototype of B-axis components, make experiment of trial cut water chamber head in turning and milling machining center, utilize test results of part's machining quality, verify unloading effects and machining accuracy of design scheme of B-axis components has been verified.
\end{abstract}

Keywords: B-axis components, Rotational structure, Turning and milling machining center, Water chamber head, Trial cut experiments, Machine accuracy.

\section{INTRODUCTION}

Diameter of nuclear water chamber head is approximately $5 \mathrm{~m}$. The blank is used about 200 to $300 \mathrm{t}$ of low-carbon low-alloy steel, for which the weight of forging blank is 30 to 50 t. Machining allowance is large. To achieve the water chamber head machining, the methods are often used large vertical lathe, floor boring and milling machine and other general machine positioning machine at domestic and foreign. As shown in Fig. (1) [1]. This method mainly exist decentralized process, many links in production organization. Processing equipments are consumed in large quantities. It is difficult to ensure the accuracy and other issues when multiple setups of worktable flipped.

To solve the problems existing in the water chamber head processing, the special turning and milling machining center is developed to meet water chamber rough machining, semifinishing and finishing. As shown in Fig. (2).

In the design of special machine, B-axis function is introduced to meet the treatment requirements in inclined the nozzle processing effectively, inclined nozzle and main body curved surface connect smoothly.

B-axis components have the function of swing. Its main structure is composed of the sliding box, rotary table, ram etc. Deformation caused by the weight of the B-axis components has affect the machining accuracy inevitably. Currently, the design of heavy machine components using simulation and optimization design method replaced empirical design [2-4].

\footnotetext{
*Address correspondence to this author at the School of Mechanical Engineering, Harbin University of Science and Technology, Heilongjiang, Harbin, 150080, P.R. China; Tel: 15004501856; Fax: +86 045186390572 ; E-mail: fx0zmh@163.com
}

And use the hardware compensation method of mechanistic correcting device [5-8]. But these measures taken are not very effective when solving the deformation error problem of nonlinear B-axis components. It is difficult to meet the Baxis design requirements.

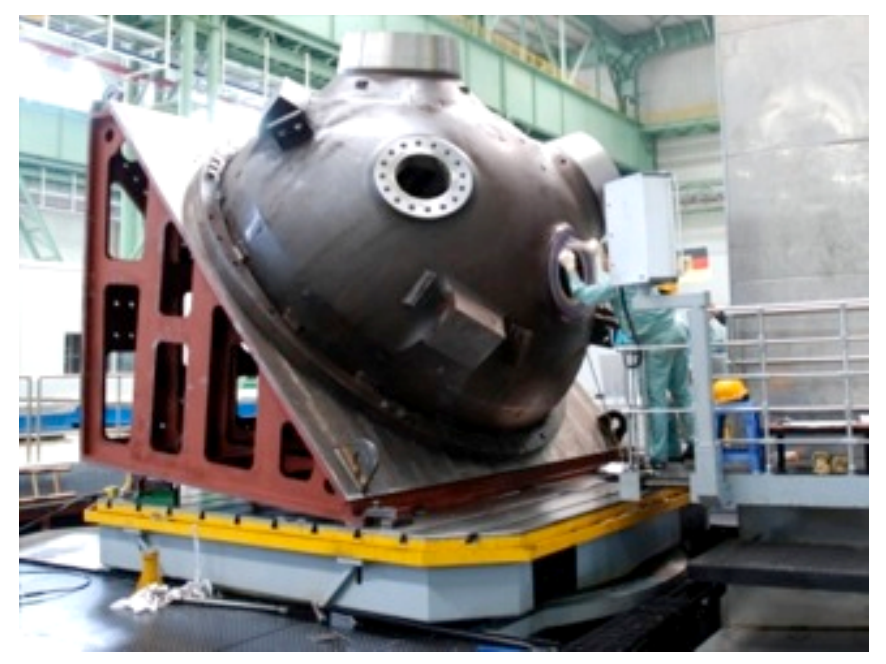

Fig. (1). Existing machining.

On the background, according to the design requirements of the water chamber head turning and milling machining center proposed the design scheme of B-axis components. To use the thermo-mechanical coupled field analysis results to study B-axis error sources and their significant impact, by the B-axis components joint surface maximum gap identification and structural design, form special machine Baxis trial production scheme, test results based on the special machine trial cut. To establish B-axis components structure to meet the requirement of water chamber head finishing. 


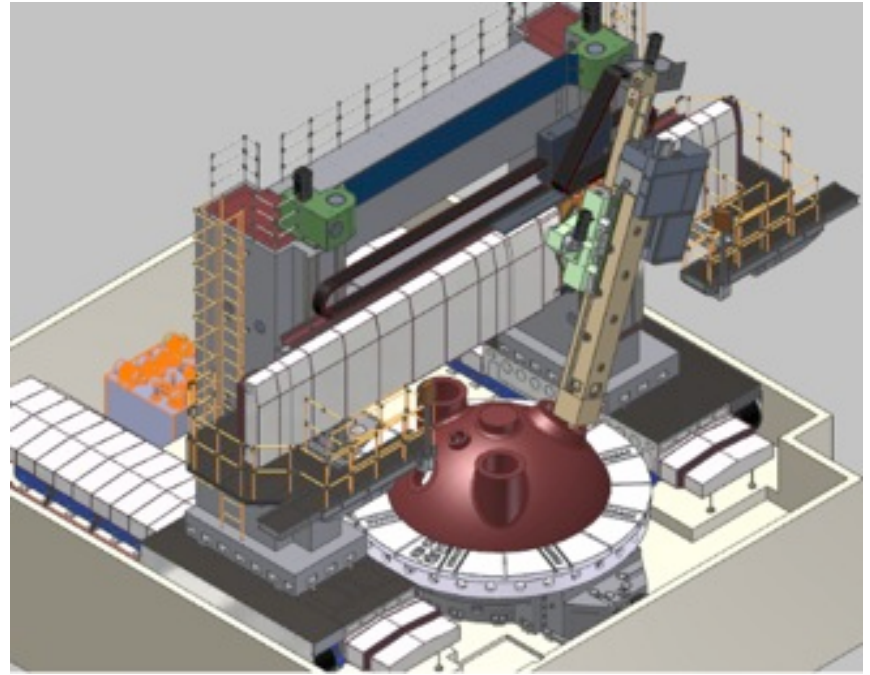

Fig. (2). Machining center.

\section{DESIGN OF B-AXIS COMPONENTS}

According to the design scheme of water chamber head turning and milling machining center. B-axis components should be designed that it can achieve the translation of $\mathrm{X}$ axis, Y-axis, Z-axis and the rotation of B-axis. Achieve automatic positioning and clamping function during processing. According to the actual machining conditions, the B-axis angle of rotation of the machine is adjustable accurate. Ensured adequate machining accuracy. Its positioning accuracy is $0.04 \mathrm{~mm}$. Ensured stiffness during machining, B-axis rotation range is $\pm 50^{\circ}$. The stroke of $\mathrm{X}$ axis, Y-axis, Z-axis respectively are $7400 \mathrm{~mm}, 4200 \mathrm{~mm}$, $1800 \mathrm{~mm}$.

To achieve the above design requirements. Use the existing mappings of heavy milling and boring spindle assembly function and structure. To obtain the component design scheme of B-axis components. As shown in Figs. (3, 4).

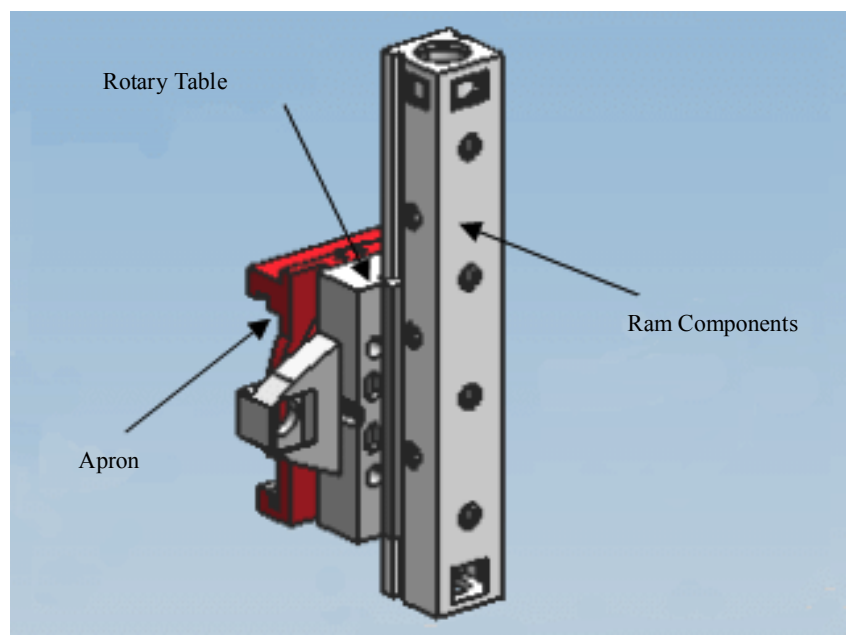

Fig. (3). Basic composition.

Slip board box of the component is installed on the machine beam. Drive on the rotary table and ram along the beam guide moving around. The rotary table and the slip board box are connected with the central axis of rotation by the radial bearings and thrust bearings, so that the rotary table and the ram can rotating around the central axis in the rotating plate (B-axis rotation), to achieve ram rotation. The front of rotary table is connected with the ram, and the rotary table upper middle position equipped with feeding device of the ram, to achieve the linear motion of the ram along $\mathrm{Z}$-axis guide.

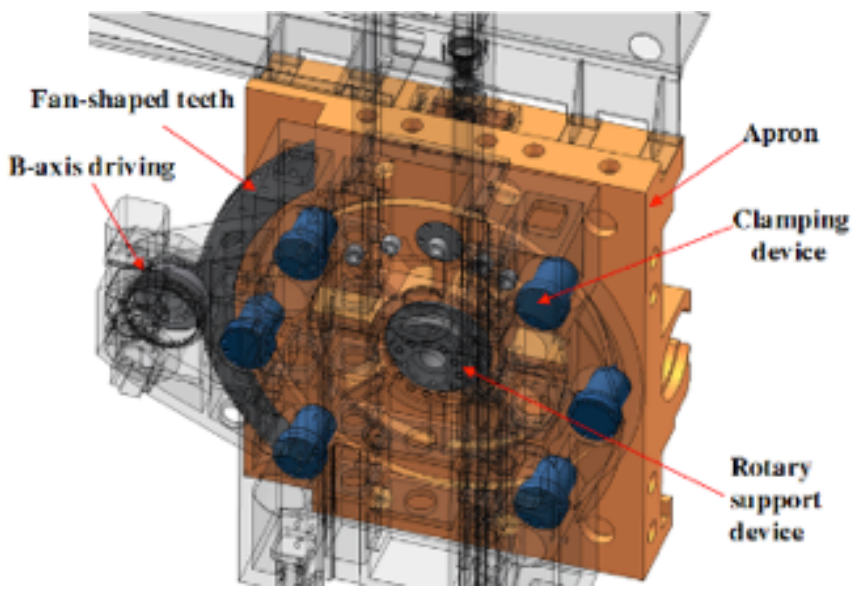

Fig. (4). Internal structure.

Structural design scheme of B-axis is expanded technology range of milling machining centers. So that the machine in one clamping positioning will be able to complete the processing of multiple inclined hole and inclined surface.

According to the positional relationship of the B-axis rotary table and slip board box and ram. Then consider the condition characteristics of B-axis. Driven B-axis spin down the drive chain has a high ratio. When the ram extends longer, cutting force will be increase significantly. At this moment, the motor will be imposed a great reversal torque. Therefore, increasing the electric brake and B-axis clamping device in the B-axis component design scheme in order to improve the stability of the B-axis assembly when working.

Since the anteversion torque generated by the gravity of the ram components will make the whole rotary table parts suffer an outward pulling force. It makes the rotary table tend to break away from the slip board box. So the rotating support structure needed to be able to withstand large axial force. For this reason, the design uses large diameter slewing steady bearings to improve the radial and axial stiffness of the B-axis rotation. There are six sets strong clamping mechanism in the B-axis rotary structure. Hydraulic release, disc spring clamp. When the need for transposition, the clamp release. After translocation in place, disc spring clamp. Each clamping means may provide about 8 tons of clamping force, a total of 48 tons.

\section{DEFORMATION CHARACTERISTIC AND ERROR COMPENSATION METHOD OF B-AXIS RAM COMPONENTS}

Ram is the key components to realize B-axis linear feed. The function is determining the position of the tool along the Z-axis by moving along the track on the rotary table. Withstand the cutting force. And cutting force will be transferred from rotary table to the cross beam. Ram 
components' error caused by deformation directly impact positioning accuracy and working stability of B-axis.

The loads which cause the deformation of the ram components include force load and thermal load. Among them, force load mainly has the gravity of the ram component itself, the centrifugal force of the boring-axis and milling-axis, varieties of support force, the friction force which generated by boring-axis and milling-axis rotating, and the cutting force which generated during the processing of the boring and milling. Heat load mainly includes environmental temperature, friction heat source and cutting heat.

Based on main cutting force equation.

$F_{c}=902 t\left(\frac{S}{n}\right)^{0.75} k$

In the formula, $k=(\mathrm{HB} / 190)^{0.40}, k$ is Hardness correction coefficient.

Calculated to B-axis components under the main cutting force $F_{c}$ in cutting water chamber head is $62710 \mathrm{~N}$, Radial force $F_{r}$ is $18813 \mathrm{~N}$, Feed force $F_{f}$ is $21948 \mathrm{~N}$.

Friction of ram components are mainly from journal friction and axis end friction, draw two types of friction torque.

$$
\begin{aligned}
& M_{f d}=\frac{4}{\pi} \cdot m \cdot f \cdot \omega^{2} \cdot r^{2} \\
& M_{f}=2 \pi f \int_{r}^{R}(p \rho) \rho d \rho=f G(R+r) / 2
\end{aligned}
$$

In the formula, $M_{f d}$ is Journal friction, $M_{f}$ is axis end friction, $m$ is quality, $f$ is friction coefficient, $\omega$ is angular velocity, $\rho$ is curvature radius, $r$ is inner diameter of axis, $R$ is outer diameter of axis, $G$ is Gravity.

Using empirical formula of Palmgren for analysis of friction heat of ram components.

$F_{1}=P_{r} \cdot\left(R_{N}-r\right) \cdot B \cdot \tan \alpha$

$Q=\frac{2 \pi n \cdot M}{60}=1.0447 \times 10^{-4} n \cdot M$

In the formula, $n$ is rotational speed ( $\mathrm{r} / \mathrm{min}), M$ is friction torque of journal or axis end $(\mathrm{N} \cdot \mathrm{mm})$.

In order to ensure its stiffness, the ram material using ZG310-570 to cast, through the secondary aging treatment, the structure is selected the square structure, layout the reinforcement in the Internal. Using the above load boundary condition and scheme, analysis the thermal coupling field of ram components, get the total deformation and boring-axis deformation of ram component. As shown in Figs. $(\mathbf{5}, \mathbf{6})$.

The results show that the range of $\mathrm{B}$-axis swing angle is from $0^{\circ}$ to $50^{\circ}$. The deformation and distribution of ram and milling-axis spindle are on the stable state. Its stiffness satisfies the design requirements. But influenced by the heat source, the error of displacement in the front end surface of ram component reaches to more than $0.016 \mathrm{~mm}$. As shown in the Fig. (7). (a) $0^{\circ}$

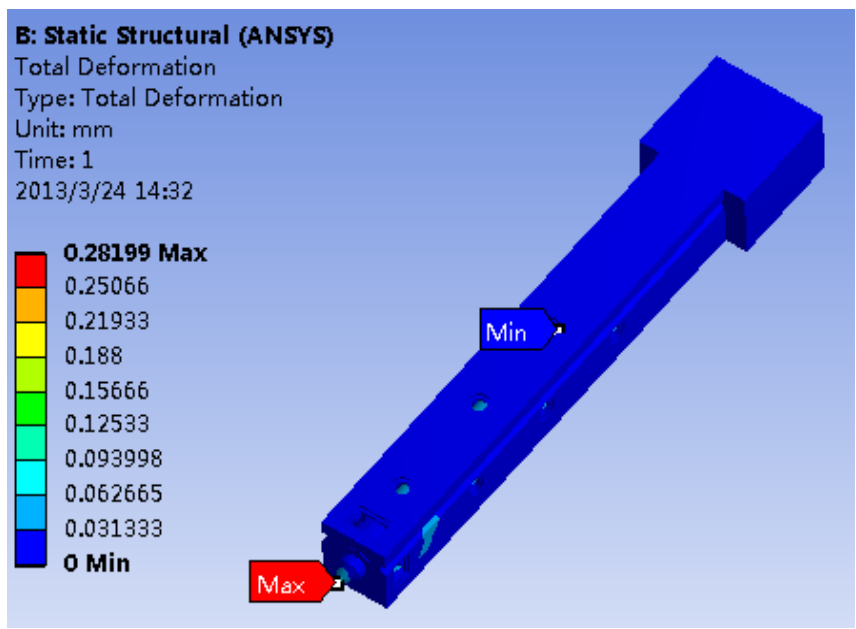

(b) $50^{\circ}$

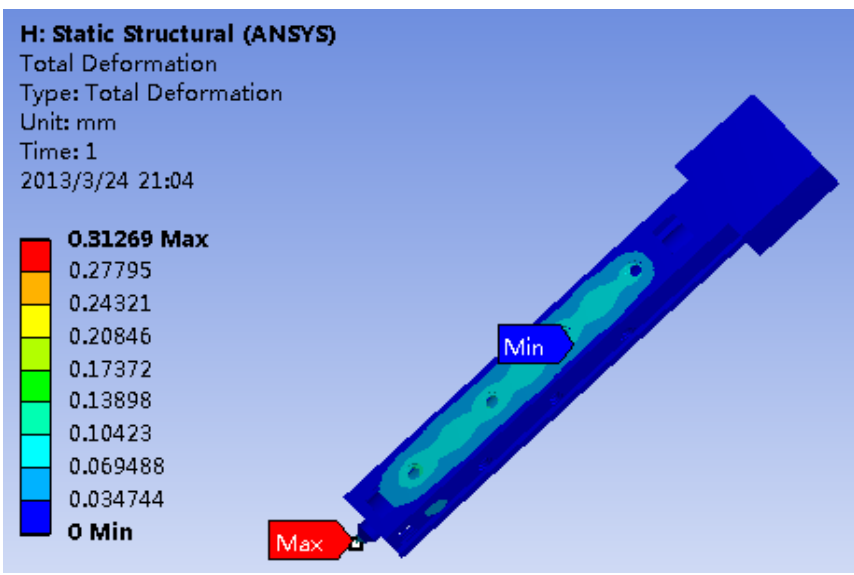

Fig. (5). Total deformation under different swing angle.

Therefore, significant analysis of double-heat coupling. Impact of any two kinds of heat sources are proven to deformation field of ram components, as shown in Fig. (8).

The results show that cutting heat has no significant effect on ram component error, environment temperature and friction heat on ram components error influence. In the whole machine tool based on cumulative error transfer to Baxis, environment temperature and friction caused by ram components deformation easily lead to its accuracy is poor.

To solve the above problems, using adjust the cutting process of the water chamber head. Improving thermal conditions of the ram components, control environment temperature and friction heat and other methods, control deformation and error of ram components. The results are shown in Table $\mathbf{1}$.

Comparative analysis shows that, the upgrade of the other indexes were all beyond $36 \%$, the regulation effect of thermal error is significant. For the design of ram components, to use the method of the regulation of the ambient temperature and a heat source of friction, it can effectively improve the B-axis positioning accuracy and stability. 
(a) $0^{\circ}$

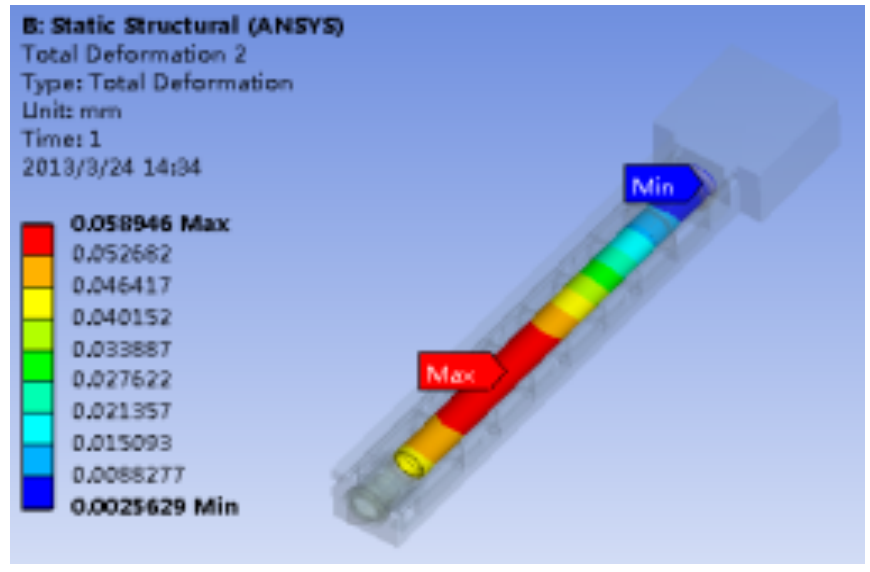

(b) $50^{\circ}$

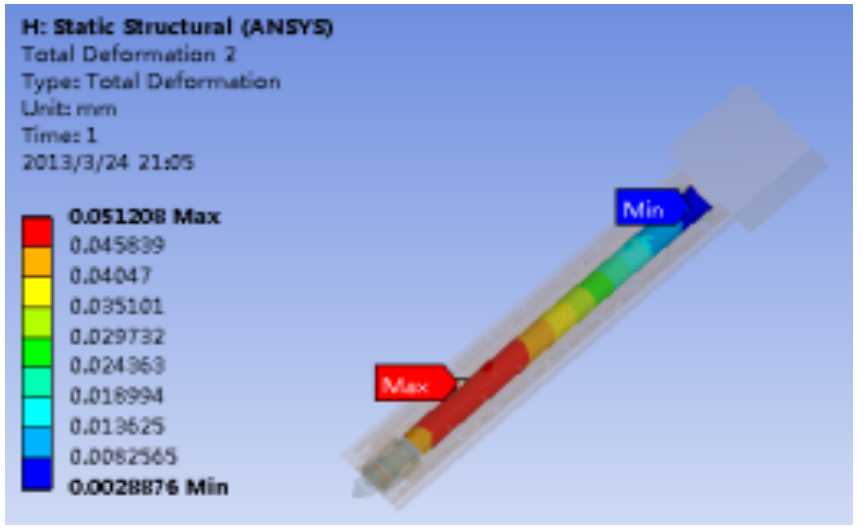

Fig. (6). Deformation under different swing angle.

(a) Dynamic error of $0^{\circ}$

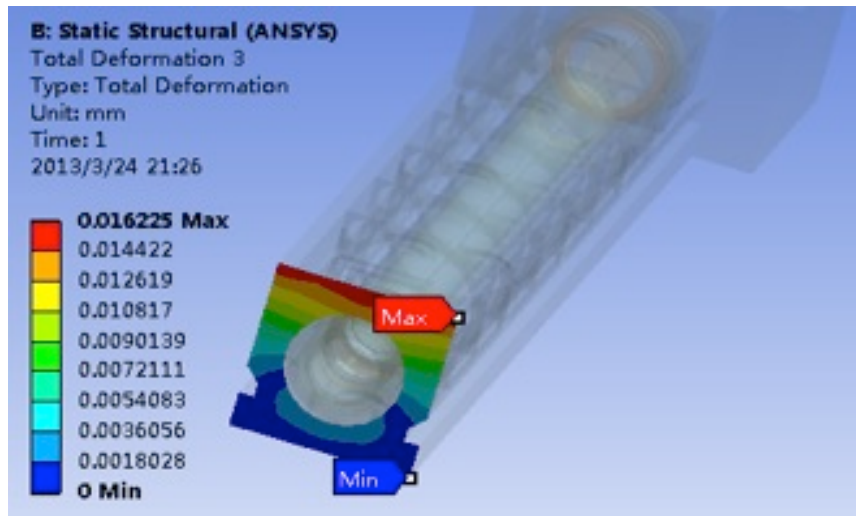

(b) Dynamic error of $50^{\circ}$

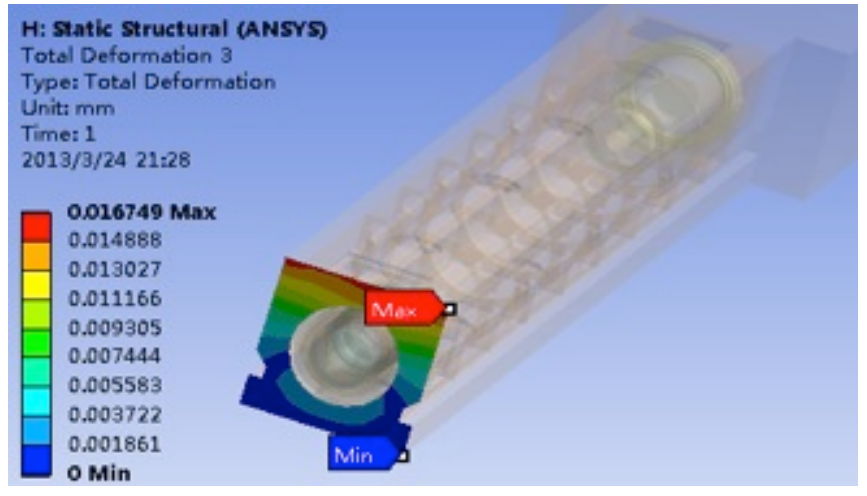

Fig. (7). Ram devices for transverse dynamic error. (a) Friction, cutting

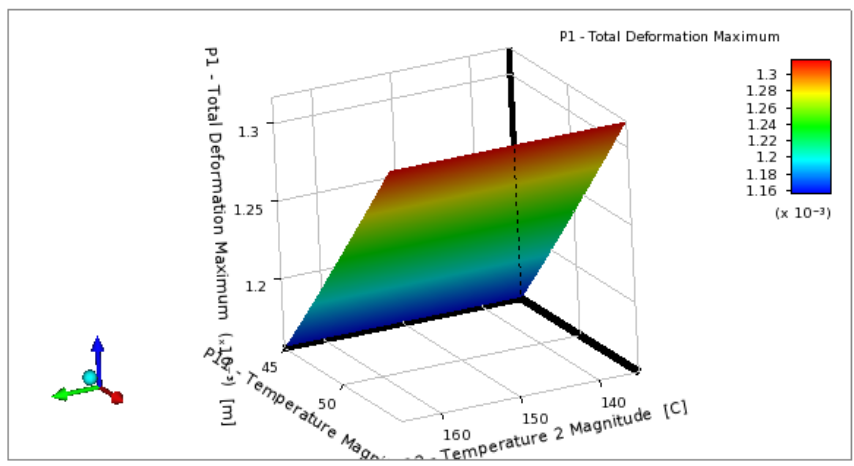

(b) Environment, cutting

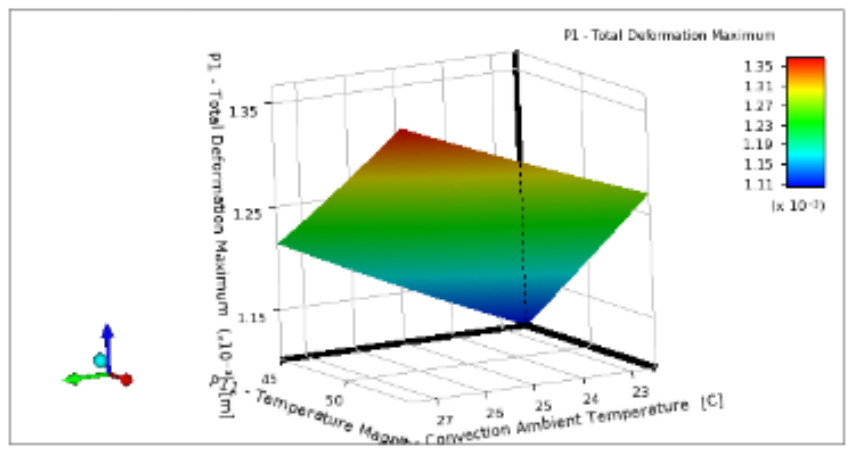

(c) Environment, friction

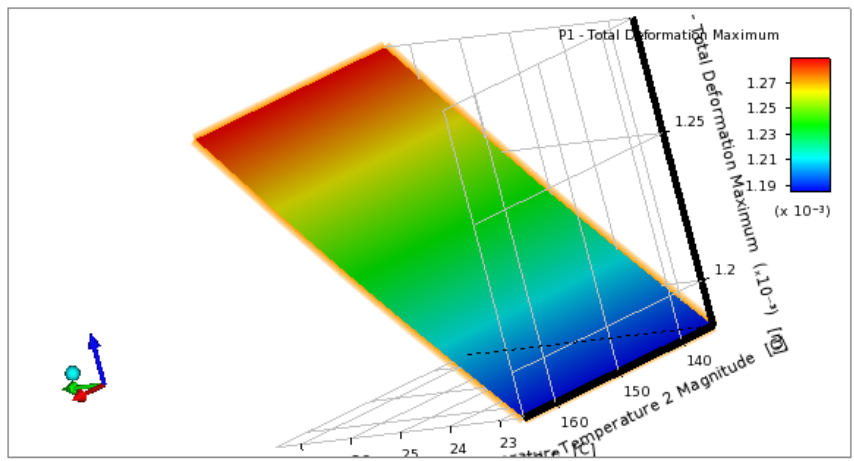

Fig. (8). Influence of heat for max deformation error.

\section{MAX GAP IDENTIFICATION OF JOINT SURFACE AND STRUCTURAL DESIGN METHOD OF B-AXIS COMPONENTS}

According to the design scheme of B-axis components, maximum gap of joint surface between rotary table and the slip board box cannot be greater than $0.04 \mathrm{~mm}$. The total weight of B-axis components is $112308 \mathrm{~N}$. When the rotary table rotating, the clamping cylinder piston will release and the positioning cylinder piston will shrinkage. At the same time, center axis will bear the weight of all overturning moment caused by the rotational parts. Under the action of this overturning moment, the deformation and displacement of B-axis components become key factor to influence the joint clearance and rotation accuracy of B-axis components.

Based on the load transfer between the B-axis components, simplifying the non-critical structure of B-axis, building the finite element model of $\mathrm{B}$-axis components to verify the reliability of B-axis components structure under 
Table 1. Ram component performance contrast effect.

\begin{tabular}{|c|c|c|c|}
\hline Evaluation Index & Indexes Uncontrolled & Indexes Controlled & Percentage Improvement \\
\hline \hline Max deformation & $0.10368 \mathrm{~mm}$ & $0.08392 \mathrm{~mm}$ & $19.059 \%$ \\
\hline Max stress & $262.12 \mathrm{MPa}$ & $58.228 \mathrm{MPa}$ & $77.786 \%$ \\
\hline Max strain field & 0.0013106 & 0.00029114 & $77.786 \%$ \\
\hline Max deformation of milling-spindle & $0.053777 \mathrm{~mm}$ & $0.029614 \mathrm{~mm}$ & $44.932 \%$ \\
\hline Max error of front end surface & $0.013887 \mathrm{~mm}$ & $0.0068002 \mathrm{~mm}$ & $51.032 \%$ \\
\hline Flatness of left guiding & $0.0082858 \mathrm{~mm}$ & $0.0052469 \mathrm{~mm}$ & $36.676 \%$ \\
\hline Flatness of right guiding & $0.0087515 \mathrm{~mm}$ & $0.0054683 \mathrm{~mm}$ & $37.516 \%$ \\
\hline
\end{tabular}

that condition. As shown in Fig. (9). To reduce the calculated amount of analyzing interaction between bearing rolling element and raceway, bearings in B-axis assembly are simplified to circular cylinders.

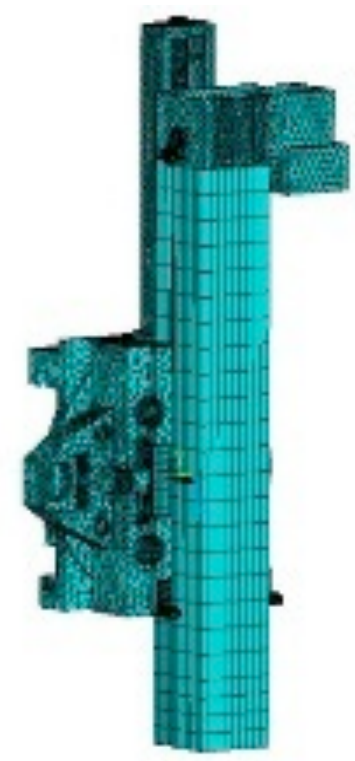

Fig. (9). Model.

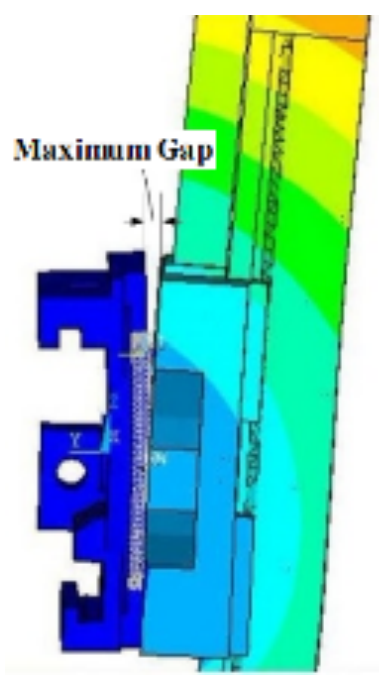

Fig. (10). Maxclearance.

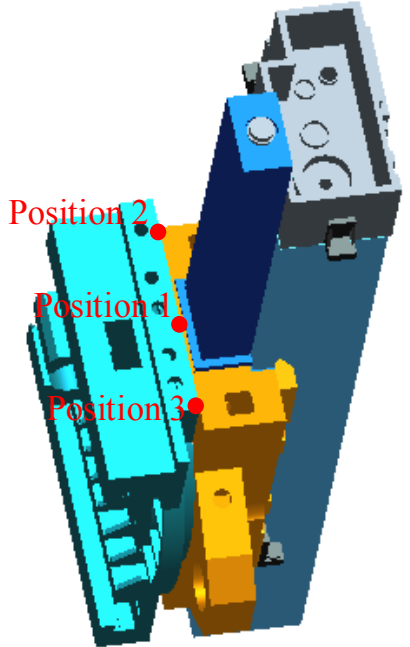

Fig. (11). Extraction.

Because of ignoring some small features in B-axis model, such as chamfering, holes and oil holes, its quality is bigger than the design quality. For example, the design quality of slip board box is $3380 \mathrm{~kg}$, while its model quality is $4350 \mathrm{~kg}$. The design quality of ram parts is $5500 \mathrm{~kg}$, but its model quality is $6692 \mathrm{~kg}$. To make the model quality consistent with the actual quality of parts, ensure the accuracy of the gravity impact analysis results, we adjust the material density of parts. So the material properties of B-axis components as shown in Table 2.

In the table, $E$ is Elastic modulus, $\mu$ is Poisson's ratio. $\rho_{t}$ is theoretical density. $\rho_{a}$ is actual density. Using the above scheme to analyze the deformation of B-axis components, found that there was a wedge gap between rotary table and slip board box under the action of overturning moment, and the biggest gap is located in the upper edge of rotary table. As shown in Fig. (10).

According to the analysis of the results, create three hard points at the edge of the slip board box and rotary joint surface. As shown in Fig. (11). By analyzing the deformation of B-axis components under the action of cutting force and clamping force, extracted the distance between node pairs corresponded to the three hard points and got the largest gap of joint surface between rotary table and the slip board box.

Analysis the maximum gap in joint surface of B-axis components by using this method, the results show that 
Table 2. Material properties of each parts.

\begin{tabular}{|c|c|c|c|c|c|}
\hline Part & Material & $\boldsymbol{E}(\mathbf{G P a})$ & $\boldsymbol{\mu}$ & $\boldsymbol{\rho}_{\boldsymbol{t}}\left(\mathbf{k g} / \mathbf{m}^{\mathbf{3}}\right)$ & $\boldsymbol{\rho}_{\boldsymbol{a}}\left(\mathbf{k g} / \mathbf{m}^{\mathbf{3}}\right)$ \\
\hline \hline Rotary table & HT300 & 143 & 0.27 & 6300 & 7300 \\
\hline Square ram & ZG310-570 & 202 & 0.3 & 5660 & 7850 \\
\hline Slip board box & HT300 & 143 & 0.27 & 7890 & 7300 \\
\hline B-axis & 45 & 209 & 0.27 & 0.27 & 7890 \\
\hline Guide & 45 & 209 & 0.3 & 7830 & 7890 \\
\hline Bearing & Bearing steel & 219 & 7830 \\
\hline
\end{tabular}

distance between three nodes are $0.0414 \mathrm{~mm}, 0.0633 \mathrm{~mm}$, $0.0311 \mathrm{~mm}$, there is distance between two nodes exceeds maximum design allowable gap that is $0.04 \mathrm{~mm}$. To meet basic function requirements of $\mathrm{B}$-axis components, improve structure design of B-axis components, as shown in Fig. (12).

The design scheme increases ring guide plate in the upper part of rotary table and slip board box. Changed open the guide into closed guide. Reduce the load in central axis by using pressure plate, to control the maximum gap in joint surface of B-axis components.

Since B-axis guide pair is vertical joint surface. Static pressure is difficult to establish. According to the static pressure unloading structure cannot effectively to solve the problem that B-axis rotary table anteversion moment excessively lead to B-axis rotation accuracy decline. Static pressure unloading replaced by mechanical roller load, and conduct inlaid steel processing in the regional where the roller is contact with the back face of rotary table directly, in order to avoid rapid wear in the bottom half of guide.

\section{ROTATION STRUCTURAL OPTIMIZATION OF B- AXIS AND TRIAL CUT EXPERIMENTS}

Based on B-axis component structure design, thermalmechanical coupling deformation regulation, guide and load structure design and maximum joint surface clearance control foundation. By using the above design trying to product B-axis component. And assembled to the water

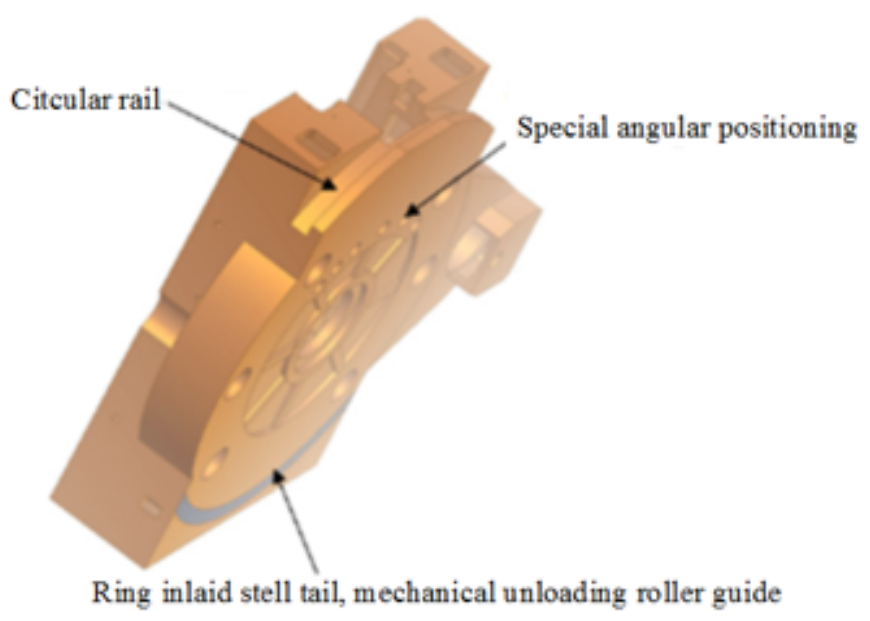

chamber head milling machining center to carry out trial cut experiment. As shown in Figs. $(13,14)$.

Experimental results show that, B-axis components meet the needs of design features. However, its positioning accuracy is influenced by the joint face gap between B-axis turntable and sliding box. Error is larger, so at larger swing angle can't met the water chamber head machining accuracy. B-axis component site detection found that ring guide pressure plate after improved can only made as three divided plates for they are restricted by the original design structure. When the rotary table going to $\pm 50^{\circ}$, only a small part of the plate is in force actually. The stiffness of pressure plate is lower, there is an unloading roller does not work.

Aiming at the above problems in the structure design of $\mathrm{B}$-axis components, replaced special cross gear bearing with double row cylindrical roller bearing. It can bear larger radial force and axial force. In the meantime, adopting the center axis in the original design. In order to avoid positioning accuracy of B-axis reducing caused by heavily force on cross gear bearing. Disc spring was installed in clamping device to produce up to $1.5 \mathrm{t}$ of thrust and strengthen the unloading efficiency. Aiming to decrease the impact of overturning moment caused by gravity. To control rotary table turning and the clearance of joint surface between rotary table and slip board box when the B-axis processing, at the top of the rotary table adopting constraint way by pressure plate. Driven design scheme is the same as the original design. By driving rotary table turning around the center axis to realize the function of B-axis's angular.

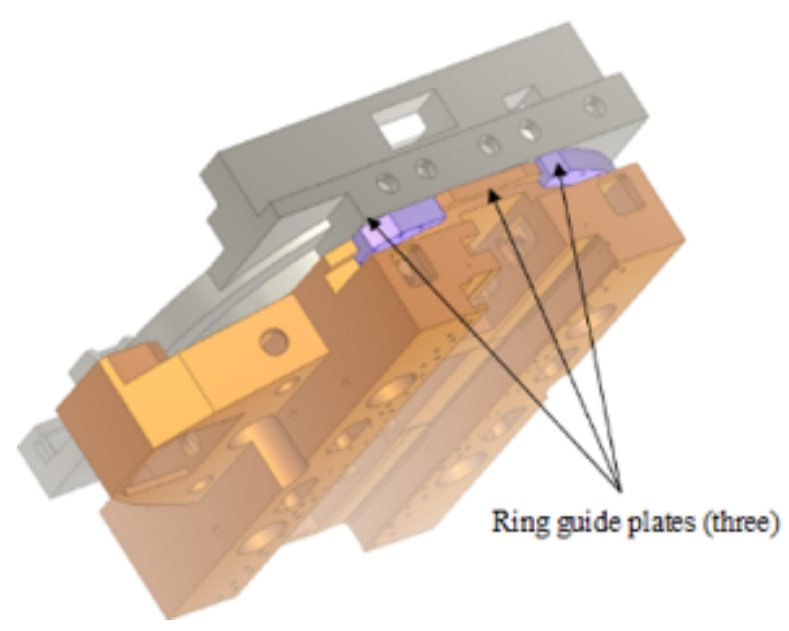

Fig. (12). Guide structure of B-axis components after improving. 

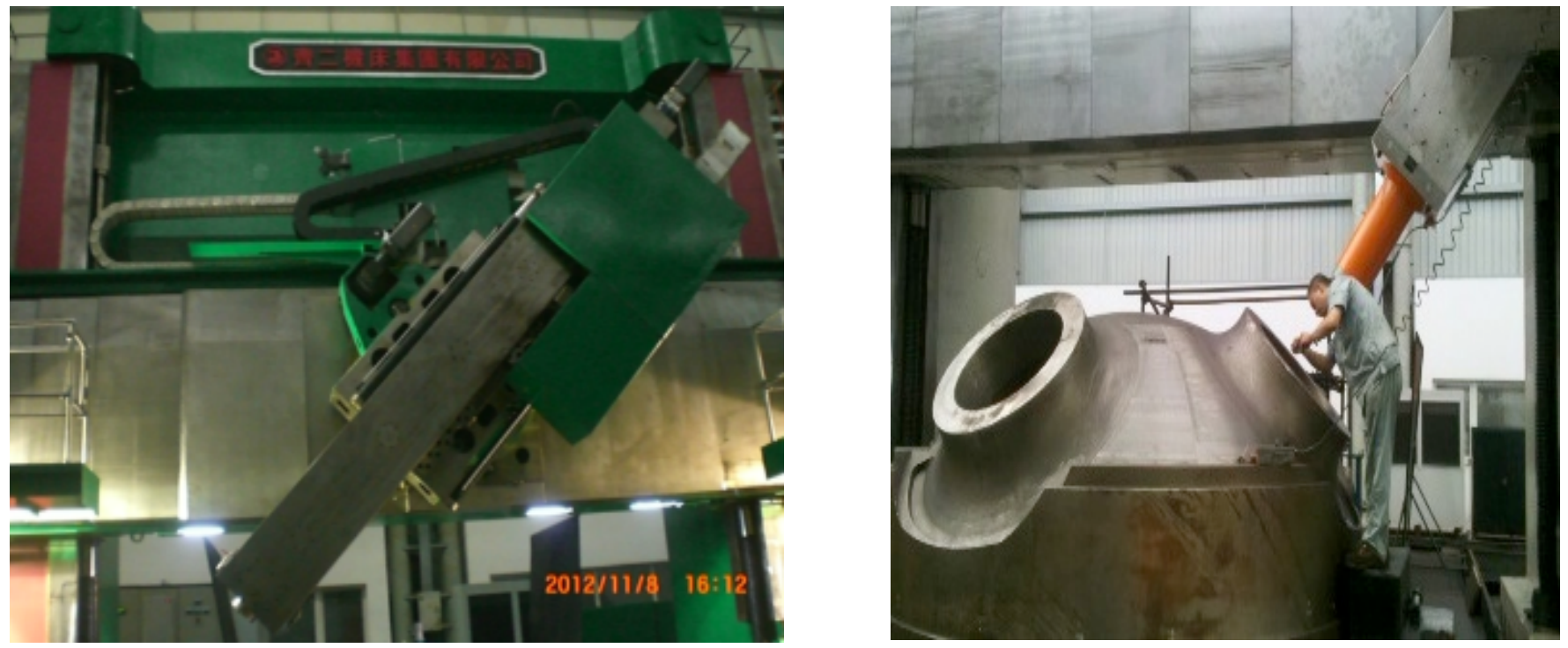

Fig. (13). Trial-cut experiment.

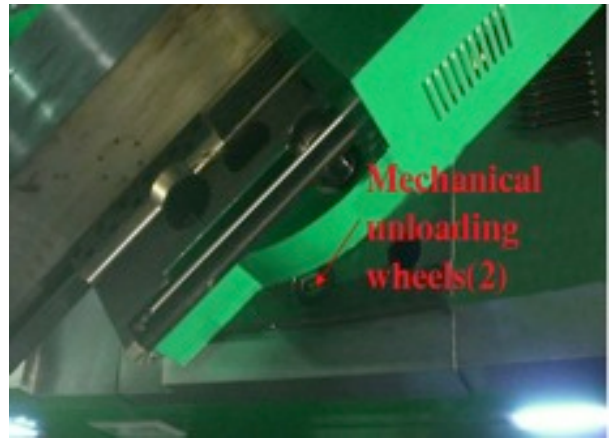

Fig. (14). Load effect test.

Using the above design, completed the rotation structural optimization of B-axis components, Trial and trial cut experiments of Water chamber head. As shown in Figs. (15, 16). The results on machining accuracy detection of Water chamber head are shown in Table 3.

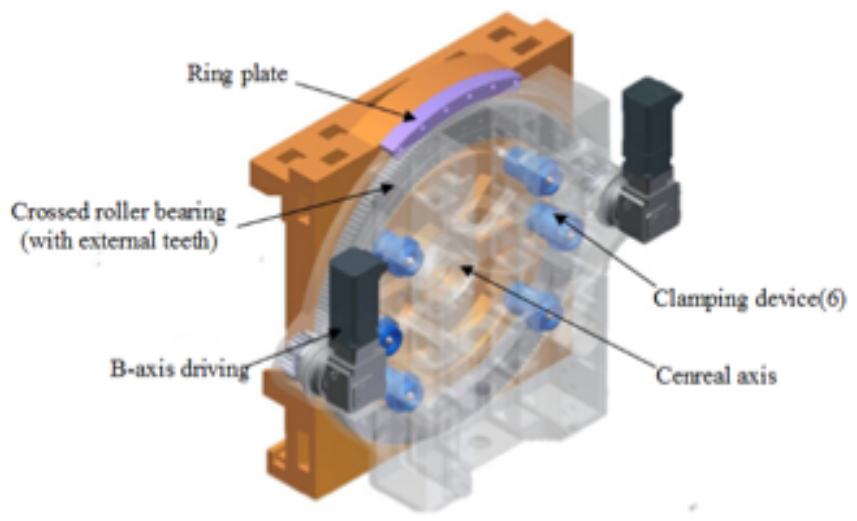

Fig. (15). Structural optimization.

In this table, I is oblique square hole width of parts. II is distance of the end face of nozzle and the base surface center. III is the shortest distance between the upper surface of rhombic holes and the base surface. IV is the angle between inner surface of the nozzle and the base surface. V is bottom diameter. VI is the distance between the bottom surface and the base surface.
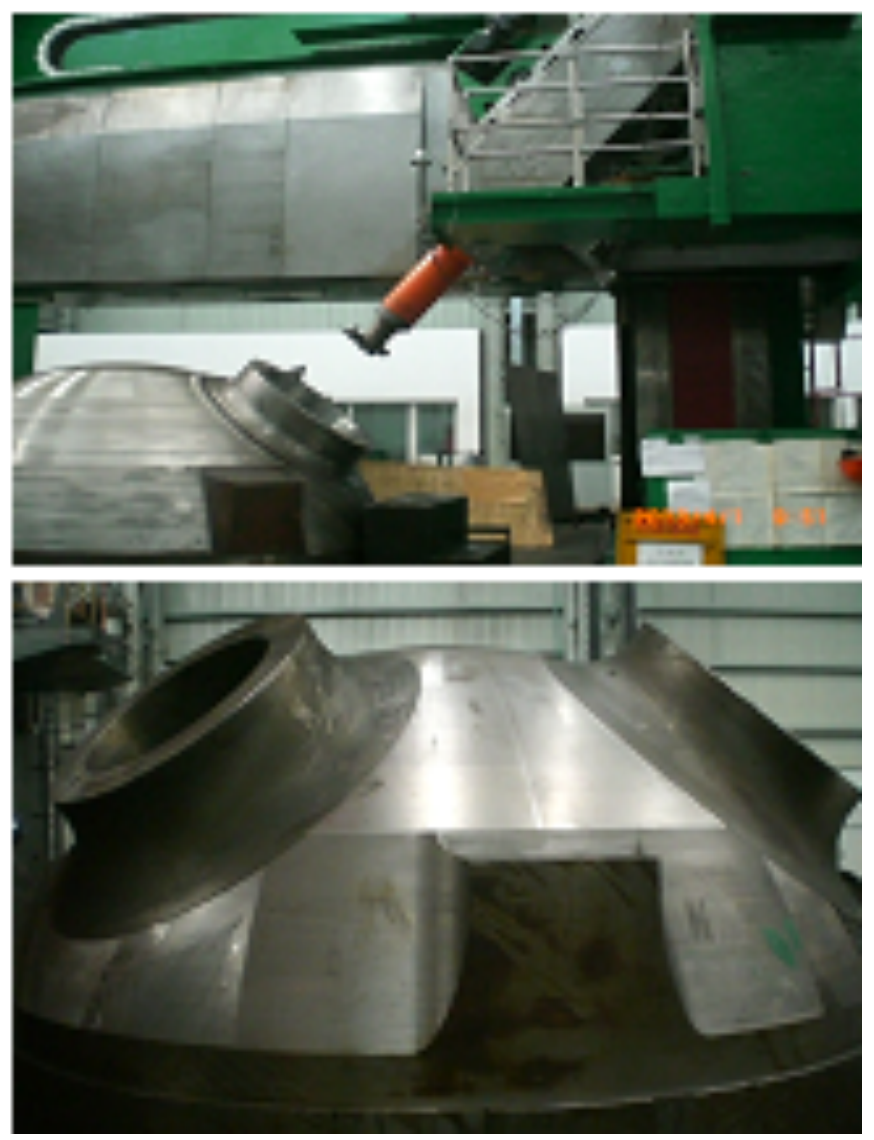

Fig. (16). Trial-cut experiments.

Machining experimental results of $\mathrm{B}$-axis show that in the $\mathrm{B}$ - axis tilt angle within a range of $\pm 50^{\circ}$. The maximum gap junction surface between the turntable and the apron is strictly controlled within $0.04 \mathrm{~mm}$. Machined surface test results of water chamber head meet the accuracy requirements completely. The optimized design makes the $\mathrm{B}$-axis rotational structure simplified. It is easier to achieve high accuracy machining of inclined hole and surface. 
Table 3. Test results of chamber head machining accuracy.

\begin{tabular}{|c|c|c|}
\hline \multirow{2}{*}{$\begin{array}{c}\text { Measure } \\
\text { Points }\end{array}$} & \multicolumn{2}{|c|}{ Drawing Requirement } \\
\cline { 2 - 3 } & Machining Accuracy & Surface Roughness \\
\hline \hline I & $405 \pm 2 \mathrm{~mm}$ & $\operatorname{Ra} 6.3 \mu \mathrm{m}$ \\
\hline II & $1791 \pm 1.5 \mathrm{~mm}$ & $\operatorname{Ra} 6.3 \mu \mathrm{m}$ \\
\hline III & $330 \pm 5 \mathrm{~mm}$ & $\operatorname{Ra} 6.3 \mu \mathrm{m}$ \\
\hline IV & $30^{\circ} \pm 0.5^{\circ}$ & $\operatorname{Ra} 6.3 \mu \mathrm{m}$ \\
\hline V & $\Phi 3440 \mathrm{~mm}$ & $\operatorname{Ra} 6.3 \mu \mathrm{m}$ \\
\hline VI & $\geq 4 \mathrm{~mm}$ & $\operatorname{Ra} 6.3 \mu \mathrm{m}$ \\
\hline
\end{tabular}

(2-2)

\begin{tabular}{|c|c|c|}
\hline \multicolumn{2}{|c|}{ Actual Measurement Results } & \multirow{2}{*}{ Testing Results } \\
\cline { 1 - 2 } Machining Accuracy & Surface Roughness & \\
\hline \hline $406 \mathrm{~mm}$ & $\mathrm{Ra} 6.3 \mu \mathrm{m}$ & Qualified \\
\hline $1792.2 \mathrm{~mm}$ & $\mathrm{Ra} 6.3 \mu \mathrm{m}$ & Qualified \\
\hline $329 \mathrm{~mm}$ & $\mathrm{Ra} 6.3 \mu \mathrm{m}$ & Qualified \\
\hline $30^{\circ}$ & $\mathrm{Ra} 6.3 \mu \mathrm{m}$ & Qualified \\
\hline$\Phi 3440 \mathrm{~mm}$ & $\mathrm{Ra} 6.3 \mu \mathrm{m}$ & Qualified \\
\hline $4 \mathrm{~mm}$ & $\mathrm{Ra} 6.3 \mu \mathrm{m}$ & Qualified \\
\hline
\end{tabular}

\section{CONCLUSION}

According to design of water chamber head turningmilling machining center. Plan the B-axis components' function. Form a design scheme of B-axis structure. Completed part design of the apron, rotary table, ram and other components. Focus on the cantilever structure characteristics of B-axis. Design B-axis clamping device to improve the stability of the B-axis components when working. Make the use of large diameter slewing bearings to improve the radial and axial stiffness of the B-axis rotation. The design expands the process scope of turning and milling machining center. So that the machine will be able to complete the processing of multiple inclined hole and inclined surfaces in one clamping positioning.

Ram selects the design of square structure and built-in reinforcement. The deformation is a steady state in the swing angle of $0^{\circ}$ to $50^{\circ}$ in the range. It meets the design requirements of stiffness. Ram components deformation caused by ambient temperature and frictional heat are the main cause of accuracy tolerance. Heat regulation makes the deformation and error of the ram components significantly reduced. Effectively improved the B-axis positioning accuracy and stability.

Building the equal mass analysis model of B-axis components and proposing the analysis method and improved design scheme of B-axis components' maximum clearance on joint surface. The analysis results on deformation and displacement of B-axis components show that there will be a wedge gap between the rotary table and slip board box and the biggest gap is located in the upper edge of rotary table. The original design scheme can't meet the design of rotary table and slip board box's clearance on joint surface. Therefore, to complete improved design of Baxis components, adopting ring guide clips, closed type guide structure and mechanical wheel unloading mechanism.

Trial cut experiment results of water chamber head show that adopting special cross instead of double-row cylindrical roller bearing, installing disc spring in the clamping device and using clamp force constraint at the top of rotary table can enhance unloading efficiency significantly and effectively reduce the overturning moment produced by the gravity. The final design scheme of B-axis components meet the requirements on design accuracy of special machine.

\section{CONFLICT OF INTEREST}

The authors confirm that this article content has no conflict of interest.

\section{ACKNOWLEDGEMENTS}

This work was financially supported by National S \& T Major Project (2011ZX04002-111).

\section{REFERENCES}

[1] H.B. Ouyang, Z.H. Yu, T. Chen, and X. FU, "Sub-Regional Process Planning for Large Nuclear Power Head", Machinery Design \& Manufacture, no. 5, pp. 253-255, May 2014.

[2] H. Shang, "The research on technology and processing of rams of heavy machine tool", Technongy and Test, no. 4, pp. 115-118, April 2012.

[3] X.X. Hua, Y. P. Zhao, and W.B. Zhang, "Vertical lathe turret ram Process Improvement", Private Technology, no. 3, p. 31, March 2011.

[4] X. Yu, "Based on the finite element structural analysis of heavy BoringMilling ram", Manufacturing Informatization, no 3, p. 31, March 2011.

[5] R. Hu, J. Cao, and M. Gao, "FEM Analysis of Turning-milling Center in Processing Slippery Pillow", Development-Innovation of MachineryElectrical Products, vol. 24, no. 5, pp. 160-162, May. 2011.

[6] S. Gheorghe, C. Romeo, and P. Anton, "Balancing-compensation system for the vertically moving elements of the machine tools with numerical control", Mechanic, vol. 46, no. 4, pp. 755-769, 2011.

[7] M. Dosedla, "How to Compensate Tool Request Position Error at Horizontal Boring Milling Machines", Recent Advances in Mechatronics 2008-2009, pp. 359-364, 2009.

[8] G. Michael, M. Josef, and F. Nils, "High accuracy grey-box model for compensation of thermal errors on 5-axis machines", CIRP AnnalsManufacturing Technology, vol. 63, no. 1, pp. 509-512, 2014. 